\title{
Molecular mode of action of CGS 9895 at $\alpha_{1} \beta_{2} \gamma_{2} \mathrm{GABA}_{\mathrm{A}}$ receptors
}

Maria C. Maldifassi, Roland Baur and Erwin Sigel

Institute of Biochemistry and Molecular Medicine, University of Bern, CH-3012 Bern, Switzerland

\section{Correspondence:}

Erwin Sigel

Bühlstrasse 28

Institute of Biochemistry and Molecular Medicine

University of Bern

Phone +41 796131046

CH-3012 Bern

Switzerland

E-mail: sigelatibmm.unibe.ch

Keywords $\mathrm{GABA}_{\mathrm{A}}$ receptors; Chloride channels; Electrophysiology; Xenopus oocyte; Benzodiazepines

\begin{abstract}
Abbreviations GABA, $\gamma$-aminobutyric acid; GABA,$\gamma$-aminobutyric type A; CGS
\end{abstract} 9865, pyrazoloquinoline 2-p-methoxyphenylpyrazolo [4,3-c] quinolin-3(5H)-one 


\section{Abstract}

$\mathrm{GABA}_{\mathrm{A}}$ receptors are the main inhibitory neurotransmitter receptors in the brain and are targets for numerous clinically important drugs such as benzodiazepines, anxiolytics and anesthetics. Previously, CGS 9895 was described as a positive allosteric modulator acting through the $\alpha+/ \beta$ - interface in the extracellular domain of $\mathrm{GABA}_{\mathrm{A}}$ receptors. The localization of the binding site was based on a steric hindrance approach, rather than on direct effects of point mutations. In the current study we further characterized modulation by this compound that seems to have six sites of action. We investigated $G_{A B A}$ receptors expressed in Xenopus laevis oocytes using voltage-clamp electrophysiology. We have identified the $\alpha_{1}$ Y209 residue present at this interface as a key residue for CGS 9895 modulation. Additionally, the interaction between this residue and various structural analogs was characterized, allowing tentative positioning of CGS 9895 versus $\alpha_{1}$ Y209 (rat sequence). Not all compounds were found to be sensitive to mutations at the $\alpha_{1}$ Y209 residue. In addition, the interaction of CGS 9895 with flurazepam was characterized. Flurazepam is hypothesized to act at the same subunit interface in the extracellular domain. We also provide evidence that the $\mathrm{GABA}_{\mathrm{A}}$ receptor harbors additional modulatory sites for CGS 9895 at each of the subunit interfaces in the trans membrane domain. 


\section{Introduction}

The major inhibitory receptor in the mammalian central nervous system is the $\gamma$-aminobutyric acid type $A\left(G A B A_{A}\right)$ receptor. This receptor is composed of five homologous subunits, arranged around a central $\mathrm{Cl}^{-}$selective channel (Macdonald et al. 1994). While 19 subunits have been cloned (Macdonald et al. 1994; Barnard et al. 1998; Olsen et al. 2008; Sigel and Steinmann 2012), the majority of GABAA receptors in the brain consist of $\alpha_{1}, \beta_{2}$ and $\gamma_{2}$ subunits (Macdonald et al. 1994; Rabow et al. 1995; Barnard et al. 1998; Olsen et al. 2008; Sigel and Steinmann 2012). Subunit composition and arrangement both affect the

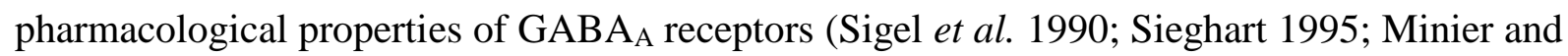
Sigel 2004). In the following we assume that the $\alpha_{1} \beta_{2} \gamma_{2}$ GABA $\mathrm{A}$ receptor has the subunit arrangement $\gamma_{2} \beta_{2} \alpha_{1} \beta_{2} \alpha_{1}$ and the $\alpha_{1} \beta_{2}$ receptor has the subunit arrangement $\beta_{2} \beta_{2} \alpha_{1} \beta_{2} \alpha_{1}$ (Baumann et al. 2001).

Several clinically and experimentally used drugs exert their action via GABA $A_{A}$ receptors, including benzodiazepines, barbiturates, and the intravenous anesthetics propofol and etomidate (Sieghart 1995; Rudolph et al. 1999; Nishikawa et al. 2002; Jurd et al. 2003; Sieghart and Ernst 2005; Li et al. 2006; Yip et al. 2013; Middendorp et al. 2014). A high affinity benzodiazepine binding site on $\alpha_{1} \beta_{2} \gamma_{2}$ GABA receptors is located at the $\alpha+\gamma-$ subunit interface in the extracellular domain (Sigel 2002; Sigel and Lüscher 2011). This site is homologous to the GABA binding sites at $\beta+/ \alpha$ - interfaces (Sigel and Buhr 1997; Sigel and Lüscher 2011). In addition to the high affinity binding site for benzodiazepines (site 1), there are other low affinity sites. One of these, site 2 , is thought to be located at the $\alpha+/ \beta$ - interface in the extracellular domain (Baur et al. 2008). Later it has been postulated that the pyrazoloquinoline CGS 9895 acts in a similar location (Ramerstorfer et al. 2011). 
Interestingly, an ethanol antagonist site at the same subunit interface has been postulated in extrasynaptic $\delta$ subunit containing receptors (Wallner et al. 2014). Other sites designated as sites 3 (Middendorp et al. 2015), are located in the membrane and have been shown to be abolished by combined mutations to isoleucine of the homologous residues $\alpha_{1} \mathrm{~S} 269, \beta_{2} \mathrm{~N} 265$, and $\gamma_{2}$ S280 (Walters et al. 2000).

It has been demonstrated that CGS 9895 at nM concentrations is a null modulator at site 1 , and at $\mu \mathrm{M}$ concentrations a positive allosteric modulator acting at the $\alpha+/ \beta$ - interface in the extracellular domain (Ramerstorfer et al. 2011). The localization of the binding site for CGS 9895 was based on a steric hindrance approach using a $18 \AA$ long reactive molecule rather than on direct interference of point mutations with modulation by this compound. The modulatory action of CGS 9895 is sensitive to the types of $\alpha$ and $\beta$ subunit isoforms present in the receptor (Ramerstorfer et al. 2011). Later, additional CGS 9895 analogues acting either as allosteric modulators or null modulators were described (Varagic et al. 2013a; Varagic et al. 2013b).

In the present study we were interested to identify point mutations interfering with modulation by CGS 9895. We show that the $\alpha_{1} \mathrm{Y} 209$ residue, specifically that located at the $\alpha+/ \beta$ - interface in $\alpha_{1} \beta_{2} \gamma_{2}$ GABA $_{A}$ receptors, is crucial for modulation of the receptor by CGS 9895. We also describe the existence of additional modulatory sites for this compound in the trans membrane domain of the $\mathrm{GABA}_{\mathrm{A}}$ receptor. 


\section{Materials and methods}

\section{Construction of mutated receptor subunits}

The point mutations $\alpha_{1}$ Y209Q, $\alpha_{1}$ Y209C, $\alpha_{1}$ Y209F, $\alpha_{1}$ S269I, $\beta_{2}$ N265I and $\gamma_{2}$ S280I were prepared using the QuikChange ${ }^{\mathrm{TM}}$ mutagenesis kit (Stratagene, Agilent Technologies, Basel, Switzerland). The numbering of amino acid residues is based on mature rat sequences.

\section{Expression of GABAA receptors in Xenopus oocytes}

Methods used were essentially as described (Middendorp et al. 2015). Briefly, capped cRNAs were synthesized (Ambion, Austin, TX, USA) from the linearized plasmids with a cytomegalovirus promotor (pCMV vectors) containing the different subunits, respectively. A poly-A tail of about 400 residues was added to each transcript using yeast poly-A polymerase (United States Biologicals, Cleveland, OH, USA). The concentration of the cRNA was quantified on a formaldehyde gel using Radiant Red stain (Bio-Rad) for visualization of the RNA. Known concentrations of RNA ladder (Invitrogen) were loaded as standard on the same gel. cRNAs were precipitated in ethanol/isoamylalcohol 19:1, the dried pellet dissolved in water and stored at $-80^{\circ} \mathrm{C}$. cRNA mixtures were prepared from these stock solutions and stored at $-80^{\circ} \mathrm{C}$.

Animal experiments were carried out in strict accordance to the Swiss ethical guidelines, and have been approved by the local committee of the Canton Bern Kantonstierarzt, Kantonaler Veterinärdienst Bern (BE85/15). Surgery of female adult Xenopus laevis was done under anesthesia (0.2\% tricaine solution). Oocytes were prepared, injected and defolliculated as described previously (Sigel 1987; Sigel and Minier 2005). Oocytes were injected with $50 \mathrm{~nL}$ of the cRNA solution containing wild-type or mutated rat $\alpha_{1}, \beta_{2}$ and $\gamma_{2}$ subunits of the 
$\mathrm{GABA}_{\mathrm{A}}$ receptors at a concentration of $10 \mathrm{nM}: 10 \mathrm{nM}: 50 \mathrm{nM}$ (Boileau et al. 2002). Injected oocytes were incubated in modified Barth's solution at $18^{\circ} \mathrm{C}$ for at least $24 \mathrm{~h}$ before the measurements.

\section{Functional characterization of the $\mathrm{GABA}_{\mathrm{A}}$ receptors}

Currents were measured essentially as described (Middendorp et al. 2015). Briefly, we used a modified two-electrode voltage clamp amplifier Oocyte clamp OC-725 (Warner Instruments, Hamden, CT, USA) in combination with a XY-recorder (90\% response time 0.1 s) or digitized at $100 \mathrm{~Hz}$ using a PowerLab 2/20 using the computer programs Chart (ADInstruments - Europe, Oxford, England). Electrodes were filled with $3 \mathrm{M} \mathrm{KCl}$ and had resistances of $0.5-0.8 \mathrm{M} \Omega$. Tests with a model oocyte were performed to ensure linearity in the larger current range. The response was linear up to $15 \mu \mathrm{A}$. The holding membrane potential was $-80 \mathrm{mV}$. The perfusion medium contained $90 \mathrm{mM} \mathrm{NaCl}, 1 \mathrm{mM} \mathrm{KCl}, 1 \mathrm{mM}$ $\mathrm{MgCl}_{2}, 1 \mathrm{mM} \mathrm{CaCl}_{2}$, and $5 \mathrm{mM}$ Na-HEPES (pH 7.4). Concentration response curves for the compounds were fitted with the equation $\mathrm{I}(\mathrm{c})=\mathrm{I}_{\max } /\left[1+\left(\mathrm{EC}_{50} / \mathrm{c}\right)^{\mathrm{n}}\right]$, where $\mathrm{c}$ is the concentration of the compound, $\mathrm{EC}_{50}$ the concentration eliciting half-maximal current amplitude, $\mathrm{I}_{\max }$ is the maximal current amplitude, I the current amplitude, and $\mathrm{n}$ is the Hill coefficient. Maximal current amplitudes ( $\mathrm{I}_{\max }$ ) were obtained from the fits of the concentration-response curves. For all receptors studied, modulation was measured at a GABA concentration eliciting $0.7-1.2 \%$ of the maximal GABA current amplitude. GABA was applied twice alone, and $45 \mathrm{~s}$ or $1 \mathrm{~min}$ applications in combination with the different compounds. The duration of washout periods was $4 \mathrm{~min}$ in between agonist or agonist/drug aplications to prevent receptor desensitization. At the beginning of the experiments, GABA applications were repeated when the elicited current amplitude altered by $>5 \%$. Potentiation 
was calculated by the following equation: (I $\left.\mathrm{I}_{\text {Modulator }+\mathrm{GABA}} / \mathrm{I}_{\mathrm{GABA}}-1\right) * 100 \%$. The perfusion solution was applied through a glass capillary with an inner diameter of $1.35 \mathrm{~mm}$, the mouth of which was placed about $0.4 \mathrm{~mm}$ from the surface of the oocyte. This allowed fast changes in agonist concentration around the oocyte. The rate of change was estimated $70 \%$ in less than 0.5 s (Sigel et al. 1990). The perfusion system was cleaned between drug applications by washing with DMSO to avoid contamination. All media contained a final concentration of 0.5 \% DMSO (v/v) to ensure drug solubility.

All data are from as a minimum of three different oocytes from at least two different batches of oocytes. Data represent mean \pm SEM. An unpaired $t$-test was used to compare two means. One-way analysis of variance (ANOVA) was used for multiple comparisons followed by a Tukey post hoc test. *, p $<0.05 ; * *, \mathrm{p}<0.01 ; * * *, \mathrm{p}<0.001$. 


\section{Results}

We were interested in determining amino acid residues important for the modulation by CGS 9895 at $\mathrm{GABA}_{\mathrm{A}}$ receptors. The $\alpha_{1}$ Y209Q mutation has been shown to abolish high affinity binding of Ro 15-1788 and flunitrazepam at the $\alpha+/ \gamma-$ at site 1 (Buhr et al. 1997). As there are two $\alpha_{1}$ subunits, there are two $\alpha_{1}$ Y209 residues in a $\alpha_{1} \beta_{2} \gamma_{2}$ receptor. We hypothesized that this mutation would possibly be able to interfere with modulators acting at the $\alpha+/ \beta-$ interface. Here, we report the $\alpha_{1}$ Y209 residue as a major determinant of CGS 9895 action.

\section{Effects of different point mutations of $\alpha_{1}$ Y209 on potentiation by CGS 9895}

We examined the consequences of different point mutations of the $\alpha_{1}$ Y209 residue on the potentiation by CGS 9895 of currents elicited by GABA. Wild-type $\alpha_{1} \beta_{2} \gamma_{2}$ receptors and three mutated receptors $\alpha_{1} \mathrm{Y} 209 \mathrm{Q} \beta_{2} \gamma_{2}, \alpha_{1} \mathrm{Y} 209 \mathrm{C} \beta_{2} \gamma_{2}$ and $\alpha_{1} \mathrm{Y} 209 \mathrm{~F} \beta_{2} \gamma_{2}$ were studied. These receptors were expressed in Xenopus oocytes, and investigated using electrophysiological techniques. Fig. 1a indicates the localization of this residue in the receptor, and Fig. 1b shows the structure of CGS 9895. For illustration, the localization of the mutations is shown in the crystalized homomeric $\beta_{3}$ receptor (Miller and Aricescu 2014), where the $\beta_{3}$ subunits were renamed $\alpha_{1}, \beta_{2}$ and $\gamma_{2}$. Fig. 2a shows original current traces obtained for wild-type $\alpha_{1} \beta_{2} \gamma_{2}$ (top) and mutated $\alpha_{1} \mathrm{Y} 209 \mathrm{Q} \beta_{2} \gamma_{2}$ (bottom) receptors. Fig. 2b summarizes the results. For all receptors studied, modulation was measured at a GABA concentration eliciting $0.7-1.2 \%$ of the maximal GABA current amplitude. It should be noted that the mutation $\alpha_{1}$ Y209Q reduces the $\mathrm{EC}_{50}$ for channel opening by GABA in $\alpha_{1} \beta_{2} \gamma_{2} \mathrm{GABA}_{\mathrm{A}}$ receptors about 2-fold (Buhr et al. 1997). Potentiation by $10 \mu \mathrm{M}$ CGS 9895 in $\alpha_{1} \beta_{2} \gamma_{2}$ receptors amounted to $336 \pm 6 \%$ (mean \pm 
SEM, $n=11$ ), and was greatly diminished in $\alpha_{1} Y 209 Q \beta_{2} \gamma_{2}$ receptors to $38 \pm 9 \%$ (mean \pm SEM, $n=4, p<0.0001$ Tukey posthoc test) and in $\alpha_{1} Y 209 C \beta_{2} \gamma_{2}$ receptors $88 \pm 24 \%$ (mean \pm SEM, $\mathrm{n}=4, \mathrm{p}<0.0001$ Tukey posthoc test). In $\alpha_{1} \mathrm{Y} 209 \mathrm{~F} \beta_{2} \gamma_{2}$ receptors potentiation was $309 \pm$ $15 \%$ (mean \pm SEM, $\mathrm{n}=4, \mathrm{p}>0.05$ Tukey posthoc test), and did not differ from the potentiation observed in wild-type receptors.

To exclude interaction with the benzodiazepine binding site located at the $\alpha+/ \gamma-$ interface, where CGS 9895 acts as a antagonist (Ramerstorfer et al. 2011), we studied the effect of potentiation on dual subunit $\alpha_{1} \beta_{2}$ receptors. Fig. 3a illustrates original traces for $\alpha_{1} \beta_{2}$ (top) and mutant $\alpha_{1} \mathrm{Y} 209 \mathrm{Q} \beta_{2}$ (bottom) receptors. Fig. 3b shows the averaged data. In $\alpha_{1} \beta_{2}$ receptors, potentiation by $10 \mu \mathrm{M}$ CGS 9895 amounted to $388 \pm 22 \%$ (mean \pm SEM, $\mathrm{n}=6$ ). In $\alpha_{1} \mathrm{Y} 209 \mathrm{Q} \beta_{2}$ receptors potentiation was reduced to $-4 \pm 4 \%$ (mean $\pm \mathrm{SEM}, \mathrm{n}=6, \mathrm{p}<$ 0.0001 Tukey posthoc test), and in $\alpha_{1}$ Y209C $\beta_{2}$ receptors to $43 \pm 14 \%$ (mean \pm SEM, $n=4, p$ $<0.0001$ Tukey posthoc test). The $\alpha_{1} \mathrm{Y} 209 \mathrm{~F} \beta_{2}$ receptor showed a similar potentiation amounting to $465 \pm 49 \%$ (mean \pm SEM, $\mathrm{n}=4$, $\mathrm{p}>0.05$ Tukey posthoc test) as compared to $\alpha_{1} \beta_{2}$ receptors.

Therefore replacement of the tyrosine in the $\alpha_{1} 209$ residue by glutamine or cysteine leads to abolishment or a reduction of modulation by CGS 9895. A more conservative mutation to phenylalanine did not affect potentiation. Our results suggest that CGS 9895 acts through the $\alpha+/ \beta$ - interface in the extracellular domain. 
Positive allosteric modulation of GABAA receptors by CGS 9895 of $\alpha_{1} \beta_{2} \gamma_{2}$ and $\alpha_{1} Y 209 Q \beta 2 \gamma_{2}$ receptors

Fig. 4 shows the concentration-response curves obtained for wild-type $\alpha_{1} \beta_{2} \gamma_{2}$ and $\alpha_{1} \mathrm{Y} 209 \mathrm{Q} \beta_{2} \gamma_{2}$ receptors. The $\alpha_{1} \beta_{2} \gamma_{2}$ receptor was characterized by an $\mathrm{EC}_{50}$ of $7.3 \pm 0.8 \mu \mathrm{M}$ (mean $\pm \mathrm{SEM}, \mathrm{n}=4$ ), and the $\alpha_{1} \mathrm{Y} 209 \mathrm{Q} \beta_{2} \gamma_{2}$ mutant receptor by an $\mathrm{EC}_{50}$ of $26 \pm 3 \mu \mathrm{M}$ (mean \pm SEM, $n=4)$. Thus, this mutation increased the EC $_{50}$ for CGS 9895 over 3-fold as compared to wild-type receptors. In addition, maximal potentiation was decreased by the mutation. In $\alpha_{1} \beta_{2} \gamma_{2}$ receptor maximal potentiation amounted to $632 \pm 148 \%$ (mean $\pm S E M, n=4$ ), and in $\alpha_{1} \mathrm{Y} 209 \mathrm{Q} \beta_{2} \gamma_{2}$ mutated receptors $252 \pm 59 \%$ (mean $\pm \mathrm{SEM}, \mathrm{n}=4$ ).

Effect of $\alpha_{1} Y 209 Q$ mutation on potentiation by different structural analogues of CGS 9895

In order to compare the different analogues, we determined the effect of the mutation at a concentration of the respective compound at the concentration effecting half maximal potentiation. We studied the effect of the above point mutation on the potentiation by the structural analogue LAU 177 (Fig. 5). A former report has indicated that this compound potentiates $\alpha_{1} \beta_{3}$ receptors expressed in Xenopus oocytes with an $\mathrm{EC}_{50}$ of $1.0 \pm 0.1 \mu \mathrm{M}$ (Varagic et al. 2013a). Fig. 1 shows the structure of all analogues studied. LAU 177 differs from CGS 9895 by different substituents in positions 4 and 8. Potentiation by $1 \mu$ M LAU 177 in $\alpha_{1} \beta_{2} \gamma_{2}$ receptors amounted to $478 \pm 37 \%$ (mean \pm SEM, $n=4$ ). In the mutated $\alpha_{1} \mathrm{Y} 209 \mathrm{Q} \beta_{2} \gamma_{2}$ receptor potentiation amounted to $304 \pm 30 \%$ (mean $\pm \mathrm{SEM}, \mathrm{n}=4, \mathrm{p}=0.011$ t-test). This indicates that LAU 177 is only partially affected by the mutation. $1 \mu \mathrm{M}$ of the benzodiazepine antagonist Ro 15-1788 did not affect the degree of potentiation in $\alpha_{1} \beta_{2} \gamma_{2}$ 
receptors. Thus, we excluded that modulation was through the high affinity benzodiazepine binding site (not shown).

We also examined the effect of the $\alpha_{1}$ Y209Q mutation on the potentiation by compounds differing from CGS 9895 only in one position, LAU 176, CGS 8216 and CGS 9896 (Fig. 1b). As above, the antagonist Ro 15-1788 excluded an action of all these compounds at the benzodiazepine binding site 1 (not shown). $10 \mu \mathrm{M}$ of the compound CGS 9896 showed a similar potentiation in mutant $\alpha_{1} \mathrm{Y} 209 \mathrm{Q} \beta_{2} \gamma_{2}$ receptors with potentiation amounting to $177 \pm 35 \%$ (mean \pm SEM, $n=4$ ) as in wild-type $\alpha_{1} \beta_{2} \gamma_{2}$ receptors, with $197 \pm$ $14 \%$ (mean \pm SEM, $\mathrm{n}=4, \mathrm{p}>0.05$ t-test). In contrast, $4 \mu \mathrm{M}$ LAU 176 showed a markedly decreased potentiation in $\alpha_{1} \mathrm{Y} 209 \mathrm{Q} \beta_{2} \gamma_{2}$ as compared to $\alpha_{1} \beta_{2} \gamma_{2}$ receptors. Potentiation in $\alpha_{1} \beta_{2} \gamma_{2}$ receptors by LAU 176 in was $1607 \pm 159 \%$ (mean \pm SEM, $\left.n=4\right)$ and in the mutated $\alpha_{1} \mathrm{Y} 209 \mathrm{Q} \beta_{2} \gamma_{2}$ receptor $249 \pm 21 \%$ (mean $\pm \mathrm{SEM}, \mathrm{n}=4, \mathrm{p}=0.0001 t$-test). For $10 \mu \mathrm{M}$ CGS 8216 potentiation was very small amounting to $56 \pm 5 \%$ (mean \pm SEM, $n=4$ ) in wild type receptors and to $-34 \pm 5 \%$ (mean \pm SEM, $n=4, p<0.0001$ t-test) in mutated $\alpha_{1} \mathrm{Y}_{209} \mathrm{Q}_{2} \gamma_{2}$ receptors.

In wild-type $\alpha_{1} \beta_{1} \gamma_{2}$ receptors, potentiation by compound LAU 176 was dramatically enhanced as compared to LAU 177, whereas it was almost lost for CGS 8216. This observation has been made previously (Varagic et al. 2013a). Replacement in position R4 of a -CN substituent of -OMe is beneficial for the pair LAU 176/ LAU 177, whereas replacement of -OMe by a -H in this position in CGS 9895 is detrimental for potentiation.

\section{Effect of $\alpha_{1} Y 209$ mutations on potentiation by flurazepam}

Since flurazepam has been hypothesized to act with low affinity at the same interface as CGS 9895, namely the $\alpha+/ \beta$ - interface at the extracellular domain (Baur et al. 2008), we wanted to 
see if the $\alpha_{1} Y 209 Q$ mutation affects the response to flurazepam. Thus, we studied the effect of the $\alpha_{1}$ Y209Q mutation in the concentration response curve for flurazepam at $\alpha_{1} \beta_{2} \gamma_{2}$ receptors (Fig. 6). As shown previously the concentration dependence potentiation is bellshaped in wild-type $\alpha_{1} \beta_{2} \gamma_{2}$ receptors (Baur et al. 2008). This bell shape has been interpreted as a positive allosteric modulation through the classical benzodiazepine site (site 1), that is counteracted by occupation of the site at the $\alpha+/ \beta$ - interface (site 2) (Baur et al. 2008). In the mutated receptor, the concentration dependence of the potentiation by flurazepam was also bell shaped but was greatly shifted to the right. As expected this mutation interferes with the action of flurazepam at the classical benzodiazepine site. At concentrations above $10 \mu \mathrm{M}$ this compound produced an increase of the current, passing through a maximum at $75-100 \mu \mathrm{M}$. Apparent affinities in wild-type receptors and the mutated receptors through site 1 were $0.4 \pm$ $0.1 \mu \mathrm{M}$ (mean $\pm \mathrm{SEM}, \mathrm{n}=9$ ) and $37 \pm 15 \mu \mathrm{M}$ (mean $\pm \mathrm{SEM}, \mathrm{n}=4$ ) respectively. Inhibition at high concentration of flurazepam has been interpreted as occupation of site 2 (Baur et al. 2008). The point mutation increased the $\mathrm{EC}_{50}$ for site 2 from $64 \pm 9 \mu \mathrm{M}$ (mean $\pm \mathrm{SEM}, \mathrm{n}=9$ ) to $147 \pm 18 \mu \mathrm{M}$ (mean $\pm \mathrm{SEM}, \mathrm{n}=4)$.

\section{Flurazepam antagonizes potentiation by CGS 9895}

Next we studied if flurazepam interferes with CGS 9895 action. For this purpose we used 100 $\mu \mathrm{M}$ and $300 \mu \mathrm{M}$ of flurazepam to counteract modulation by this compound. At these concentrations flurazepam shows reduced or no potentiation response of $\alpha_{1} \beta_{2} \gamma_{2} \mathrm{GABA}_{\mathrm{A}}$ receptors (Fig. 6) (Baur et al. 2008). $10 \mu \mathrm{M}$ of CGS 9895 potentiated the response of $\alpha_{1} \beta_{2} \gamma_{2}$ receptors by $347 \pm 11 \%$ (mean $\pm S D, n=3$ ). Subsequently, the same oocytes were exposed to the combination of $10 \mu \mathrm{M}$ CGS 9895 and $100 \mu \mathrm{M}$ of flurazepam, and a residual 
potentiation amounting to $151 \pm 10 \%$ (mean \pm SD, $n=3$ ) was observed. In another set of experiments, $10 \mu \mathrm{M}$ of CGS 9895 potentiated the response of $\alpha_{1} \beta_{2} \gamma_{2}$ receptor by $323 \pm 10 \%$ (mean $\pm \mathrm{SEM}, \mathrm{n}=4$ ). When the same oocytes were exposed to the combination of $10 \mu \mathrm{M}$ CGS 9895 and $300 \mu \mathrm{M}$ of flurazepam residual potentiation of $18 \pm 4 \%$ (mean \pm SEM, $n=4$ ) was obtained. An original current trace of the latter experiment is shown in Fig. 7. As shown in Fig. 6 at a concentration of $300 \mu \mathrm{M}$, flurazepam alone nearly fails to affect current elicited by GABA. In $\alpha_{1} \beta_{2}$ receptors $10 \mu \mathrm{M}$ of CGS 9895 potentiated the response by $329 \pm 37 \%$ (mean \pm SEM, $n=4$ ), subsequently the same oocytes were exposed to the combination of 10 $\mu \mathrm{M}$ CGS 9895 and $300 \mu \mathrm{M}$ of flurazepam where potentiation amounted to $73 \pm 19 \%$ (mean \pm SEM, $n=4)$. The above results indicate that the ability of flurazepam to inhibit modulation by CGS 9895 could be mediated via the same site in the extracellular $\alpha+/ \beta$ - interface. Alternatively, both modulatory sites must communicate or the effect of their occupation converges at the GABA binding site or on channel gating.

\section{Possible additional sites of action of CGS 9895}

Although our observations suggest involvement of the $\alpha_{1}$ Y209 residue situated at the extracellular $\alpha+/ \beta$ - interface in the potentiation by CGS 9895, this compound could still act additionally at other sites in the receptor. Previously, we and others have observed that many hydrophobic substances act at the low affinity site for diazepam on GABAA receptors located at subunit interfaces in the trans membrane region (site 3). We wondered if CGS 9895 would also act at these sites. Triple mutant $\alpha_{1} \mathrm{~S} 269 \mathrm{I} \beta_{2} \mathrm{~N} 265 \mathrm{I} \gamma_{2} \mathrm{~S} 280 \mathrm{I}$ receptor has previously been shown to lack low affinity diazepam sites (Walters et al. 2000). Each mutation is located at different receptor interfaces. Wild-type receptors, $\alpha_{1} S 269 \mathrm{I} \beta_{2} \gamma_{2}, \alpha_{1} \beta_{2} \mathrm{~N} 265 \mathrm{I} \gamma_{2}, \alpha_{1} \beta_{2} \gamma_{2} \mathrm{~S} 280 \mathrm{I}$ and 
$\alpha_{1}$ S269I $\beta_{2}$ N265I $\gamma_{2}$ S280I were expressed and investigated. The mutated receptors are abbreviated here as $\alpha_{1} \mathrm{M}, \beta_{2} \mathrm{M}, \gamma_{2} \mathrm{M}$, and $\alpha_{1} \mathrm{M} \beta_{2} \mathrm{M} \gamma_{2} \mathrm{M}$. The potency of GABA for channel gating in all these mutated receptors has previously been described (Maldifassi et al. 2016). In order to exclude general gating effects caused by these mutations we showed that potentiation by low concentrations of diazepam and by THDOC were not affected (Maldifassi et al. 2016).

First we characterized in each receptor the concentration-response relationship for the modulation by diazepam. As shown in Fig. 8a, in wild-type and all mutated receptor forms $\mathrm{nM}$ concentrations of diazepam potentiated GABA elicited currents. In $\alpha_{1} \beta_{2} \gamma_{2}$ and $\alpha_{1} \beta_{2} \gamma_{2} \mathrm{M}$ receptors the first phase of potentiation reached a plateau at approximately $0.3 \mu \mathrm{M}$ of diazepam. An inhibitory phase was observed at wild-type $\alpha_{1} \beta_{2} \gamma_{2}$ receptors at 3-10 $\mu \mathrm{M}$ diazepam and an additional phase of potentiation for both receptors was evident at concentrations above 10-30 $\mu \mathrm{M}$. Mutated $\alpha_{1} \mathrm{M} \beta_{2} \gamma_{2}, \alpha_{1} \beta_{2} \mathrm{M} \gamma_{2}$, and $\alpha_{1} \mathrm{M} \beta_{2} \mathrm{M} \gamma_{2} \mathrm{M}$ receptors lacked this low affinity potentiation by diazepam. The curve was bell-shaped. At high concentrations, approximately $10 \mu \mathrm{M}$ and above, diazepam produced a significant inhibition of the response to GABA in $\alpha_{1} M \beta_{2} \gamma_{2}, \alpha_{1} \beta_{2} M \gamma_{2}$, and $\alpha_{1} M \beta_{2} M \gamma_{2} M$ receptors.

Subsequently, we determined the effect of individual site 3 mutations and the triple mutation on potentiation by $10 \mu \mathrm{M}$ CGS 9895, $10 \mu \mathrm{M}$ LAU 177 and $200 \mu \mathrm{M}$ of diazepam. As shown in Fig. 8b, in $\alpha_{1} \mathrm{M} \beta_{2} \gamma_{2}$ receptors potentiation by $10 \mu \mathrm{M}$ CGS 9895 was increased to $614 \pm 123 \%$ (mean \pm SEM, $\mathrm{n}=5, \mathrm{p}=0.007$ Tukey posthoc test) as compared to wild-type receptors, where potentiation amounted to $337 \pm 6 \%$ (mean \pm SEM, $n=11$ ) respectively. Potentiation by CGS 9895 was reduced in the $\alpha_{1} \beta_{2} \mathrm{M} \gamma_{2}$ receptor mutant to $115 \pm 15 \%$ (mean \pm SEM, $\mathrm{n}=4, \mathrm{p}=0.007$ Tukey posthoc test). In $\alpha_{1} \beta_{2} \gamma_{2} \mathrm{M}$ receptors potentiation was increased and amounted to $496 \pm 117 \%$ (mean \pm SEM, $\mathrm{n}=4, \mathrm{p}=0.049$ Tukey posthoc test). 
Potentiation of the GABA response in $\alpha_{1} \mathrm{M} \beta_{2} \mathrm{M} \gamma_{2} \mathrm{M}$ receptors was reduced to $89 \pm 9 \%$ (mean \pm SEM, $\mathrm{n}=7, \mathrm{p}=0.004$ Tukey posthoc test).

The single mutations in the $\alpha_{1}$ and in the $\beta_{2}$ subunits altered the degree of potentiation by $10 \mu \mathrm{M}$ LAU 177. Modulation was also strongly impaired in the triply mutated $\alpha_{1} \mathrm{M} \beta_{2} \mathrm{M} \gamma_{2} \mathrm{M}$ receptors. Potentiation by $10 \mu \mathrm{M}$ LAU 177 in wild-type $\alpha_{1} \beta_{2} \gamma_{2}$ receptors was $796 \pm 129 \%$ (mean $\pm \mathrm{SEM}, \mathrm{n}=6)$, in the mutated $\alpha_{1} \mathrm{M} \beta_{2} \gamma_{2}$ receptor $390 \pm 65 \%$ (mean \pm SEM, $n=4, p=0.0416$ Tukey posthoc test), and in $\alpha_{1} \beta_{2} \mathrm{M} \gamma_{2}$ receptors amounted to $0.3 \pm 4.4$ $\%$ (mean \pm SEM, $\mathrm{n}=4, \mathrm{p}=0.0001$ Tukey posthoc test). In the triple mutated receptor $\alpha_{1} \mathrm{M} \beta_{2} \mathrm{M} \gamma_{2} \mathrm{M}$ potentiation was $17 \pm 12 \%$ (mean $\pm \mathrm{SEM}, \mathrm{n}=4, \mathrm{p}=0.0002$ Tukey posthoc test).

Potentiation by $200 \mu \mathrm{M}$ diazepam was affected by all mutations. Potentiation in wildtype receptors amounted to $348 \pm 68 \%($ mean \pm SEM, $n=4)$ and was reduced to $63 \pm 13 \%$ (mean \pm SEM, $n=4, p=0.0257$ Tukey posthoc test) in the $\alpha_{1} \mathrm{M} \beta_{2} \mathrm{M} \gamma_{2} \mathrm{M}$ receptor. For the individually mutated receptors potentiation amounted to $55 \pm 17 \%$ in $\alpha_{1} \mathrm{M} \beta_{2} \gamma_{2}$ (mean $\pm \mathrm{SEM}$, $\mathrm{n}=4, \mathrm{p}=0.036$ Tukey posthoc test), $-52 \pm 16 \%$ in $\alpha_{1} \beta_{2} \mathrm{~N} 265 \mathrm{I} \gamma_{2}$ (mean $\pm \mathrm{SEM}, \mathrm{n}=4, \mathrm{p}=$ 0.016 Tukey posthoc test) and to $974 \pm 175 \%$ in $\alpha_{1} \beta_{2} \gamma_{2} \mathrm{M}$ receptor (mean $\pm \mathrm{SEM}, \mathrm{n}=4, \mathrm{p}=$ 0.0012 Tukey posthoc test). In this case, the $\alpha_{1} \mathrm{M}$ mutation may convert CGS 9895 into a negative allosteric modulator.

The above data suggest that additional modulatory sites for CGS 9895 are present at the $\alpha+/ \beta-, \beta+/ \alpha-, \gamma+/ \beta-$, and $\alpha+/ \gamma-$ subunit interfaces located in the trans membrane domain of $\mathrm{GABA}_{\mathrm{A}}$ receptors. On the other hand, the structural analog LAU 177 may harbor modulatory sites at the $\alpha+/ \gamma-$ and $\beta+/ \alpha-$ subunit interfaces. GABAA receptors harbor modulatory sites 3 
for diazepam at $\alpha+/ \beta-, \beta+/ \alpha-, \gamma+/ \beta-$, and $\alpha+/ \gamma-$ subunit interfaces in the trans membrane domain.

\section{Discussion}

The pyrazoloquinoline CGS 9895 at nM concentrations was described as an antagonist at the benzodiazepine high affinity site, but at $\mu \mathrm{M}$ concentrations enhanced GABA induced currents in $\alpha_{1} \beta_{3}$ and $\alpha_{1} \beta_{3} \gamma_{2}$ receptors (Ramerstorfer et al. 2011). Using a steric hindrance approach together with a homology model of $\mathrm{GABA}_{\mathrm{A}}$ receptors (Ernst et al. 2005), several possible pocket-forming amino acids at the $\alpha+/ \beta$ - subunit interface were mutated to cysteine. Modification with MTSEA-biotin of the mutated residues $\alpha_{1}$ S204C, $\alpha_{1}$ V211C and $\beta_{3} 64 \mathrm{C}$ considerably reduced modulation by CGS 9895, indicating that this compound acts within 18 $\AA$ of the mutated residues (Ramerstorfer et al. 2011). Because of the length and flexibility of MTSEA-biotin, specific amino acids in contact with CGS 9895 were not identified (Ramerstorfer et al. 2011). Our results indicate that the $\alpha_{1}$ Y209 residue located at the $\alpha+/ \beta-$ interface is important for CGS 9895 action and additionally suggest binding sites at all five subunit interfaces in the trans membrane region.

As the $\alpha_{1} \beta_{2} \gamma_{2}$ receptor contains two $\alpha_{1}$ subunits, there are two $\alpha_{1} Y 209$ residues in the receptor. One residue is located at the $\alpha+\gamma$ - interface in the extracellular domain of the receptor (site 1), and is part of the diazepam-binding pocket (Amin et al. 1997; Buhr et al. 1997). The other residue is located at the extracellular part of the $\alpha+/ \beta$ - interface homologous to the residue located at site 1 . Mutation to Q of the $\alpha_{1} \mathrm{Y} 209$ residue leads to loss of Ro151788 and flunitrazepam binding at the high affinity diazepam site and reduces the $\mathrm{EC}_{50}$ for channel opening by GABA about 2-fold (Buhr et al. 1997). We studied if the mutation of this 
residue might also interfere with the action of modulators supposedly acting at the extracellular $\alpha+/ \beta-$ interface.

We found that mutations in the $\alpha_{1}$ Y209 residue affected the ability of CGS 9895 to potentiate GABA elicited currents at $\mathrm{GABA}_{\mathrm{A}}$ receptors. Replacement of tyrosine in the $\alpha_{1} 209$ residue for the non-aromatic amino acids glutamine or cysteine, led to a dramatic reduction on the action of CGS 9895. When the same tyrosine residue was replaced with phenylalanine, leading to the removal of the hydroxyl group in the benzene ring, potentiation remained almost unaffected. Thus, the aromatic ring in the $\alpha_{1}$ Y209 residue is essential for the interaction of the receptor with CGS 9895. The $\alpha_{1}$ Y209Q mutation led to an increase of the EC50 for CGS 9895, and a decrease in the maximal potentiation obtained. Similar observations were made in $\alpha_{1} \beta_{2}$ and $\alpha_{1} \beta_{2} \gamma_{2}$ receptors, indicating that indeed the residue at the $\alpha+/ \beta$ - subunit interface is important. It should be noted that in case a point mutation affects modulation by a compound, the corresponding residue can be involved in the formation of the binding pocket, or alternatively it may affect the allosteric transduction required for modulation. At least the ability of GABA to gate the channel is nearly unaffected by the $\alpha_{1}$ Y209Q mutation (Buhr et al. 1997).

Structural analogs of CGS 9895 were investigated for their sensitivity to mutations in the $\alpha_{1}$ Y209 residue. All compounds investigated contained a common pyrazoloquinolinone nucleus, with different substituents in R4 and R8 (Fig. 1b). EC 50 and efficacy (10 $\mu \mathrm{M})$ of the compounds in $\alpha_{1} \beta_{3}$ receptors have been described elsewhere (Varagic et al. 2013a). CGS 9895 and LAU 176, are both sensitive to the studied mutation, and have both a -OMe group at position R4, but they differ in the R8 position, where the first has a - $\mathrm{H}$ and the latter a $-\mathrm{OMe}$ group. Potentiation by CGS 9896 is not significantly affected and that by LAU 177 partially by the $\alpha_{1}$ Y209Q mutation. CGS 9896 has a $-\mathrm{Cl}$ at position $\mathrm{R} 4$, and at $\mathrm{R} 8$ a hydrogen atom. 
LAU 177 has a -CN group at the position R4, and a -OMe group at R8. CGS 8216, which contains $-\mathrm{H}$ in both positions was the weakest modulator of GABA currents in $\alpha_{1} \beta_{2} \gamma_{2}$ receptors. A similar result was obtained previously using $\alpha_{1} \beta_{3}$ receptors (Varagic et al. 2013a). From our observations we conclude that the methoxy group at the R4 may be responsible for the sensitivity of these compounds to the $\alpha_{1}$ Y209Q mutation and might be apposed to this residue.

Previously, a low affinity site for flurazepam has been postulated at the $\alpha+/ \beta$ - subunit interface. We were interested if flurazepam and CGS 9895 interacted at the same site. We found a) that the mutation $\alpha_{1}$ Y209Q not only affects modulation by CGS 9895 but also affects the affinity of flurazepam to site 2 and b) that $300 \mu \mathrm{M}$ flurazepam almost completely prevented modulation by CGS 9895. These results could indicate that flurazepam and CGS 9895 may share a site of action at the $\alpha+/ \beta$ - extracellular interface. Different conclusions have been reached earlier. High concentrations of flurazepam were described to partially prevent the action of CGS $9895(10 \mu \mathrm{M})$ in $\alpha_{1} \beta_{3} \mathrm{GABA}_{\mathrm{A}}$ receptors, and to inhibit GABA mediated currents (Ramerstorfer et al. 2011). Since this negative modulatory effect could not be abolished by modification with MTSEA-biotin of $\alpha_{1}$ S204C, $\alpha_{1}$ V211C and $\beta_{3} 64 C$, the authors concluded that flurazepam effects must be mediated through a different site (Ramerstorfer et al. 2011).

The five-subunit interfaces of GABAA receptors harbor modulatory sites for high concentrations of diazepam (sites 3). We also investigated if CGS 9895 is affected by mutations in these sites. Potentiation by CGS 9895 was reduced in the triple mutant receptor and by the $\beta_{2}$ N265I mutation, and increased by the mutations $\alpha_{1}$ S269I and $\gamma_{2}$ S280I. We concluded that the five-subunit interfaces of $\mathrm{GABA}_{\mathrm{A}}$ receptors bear modulatory sites for CGS 9895. The fact the $\beta_{1}$ S290N mutation leads to loss of stimulation by CGS 9895 in $\alpha_{1} \beta_{1}$ 
receptors (Ramerstorfer et al. 2011) were previously interpreted as allosteric effect. The structural analog LAU 177 was also sensitive to some of the site 3 mutations. Potentiation was reduced in the triple mutant receptor, as by the $\alpha_{1}$ S269I and $\beta_{2}$ N265I mutations, however it was not affected by the $\gamma_{2}$ S280I mutation. Therefore only the $\beta+/ \alpha-, \alpha+/ \beta-$, and $\alpha+/ \gamma-$ $\mathrm{GABA}_{\mathrm{A}}$ receptor subunit interfaces have modulatory sites for this compound.

In summary, we show that $\alpha_{1}$ Y209 at the $\alpha+/ \beta$ - interface in the extracellular domain is a key residue for CGS 9895 action in $\mathrm{GABA}_{\mathrm{A}}$ receptors and that it may be in contact with the -OMe substituent of this compound. Additionally, the $\mathrm{GABA}_{\mathrm{A}}$ receptor harbors modulatory sites for this compound at subunit interfaces in the membrane.

\section{Acknowledgements and conflict of interest disclosure}

This work was supported by the Swiss National Science Foundation grant 315230_156929/1. M.C.M. is a recipient of a fellowship (Beca Chile Postdoctorado from CONICYT, Ministerio de Educacion, Chile). LAU 177, CGS 9896, CGS 8216 and LAU 176 were gifts from M. Ernst, Department of Biochemistry and Molecular Biology, Medical University Vienna. The authors declare no conflict of interests.

All experiments were conducted in compliance with the ARRIVE guidelines. 


\section{References}

Amin J., Brooks-Kayal A. and Weiss D.S. (1997) Two residues on the $\alpha$ subunit are crucial for benzodiazepine binding and allosteric modulation of gamma-aminobutyric acid A receptors. Mol. Pharmacol. 51, 833-841.

Barnard E.A., Skolnick P., Olsen R.W., Möhler H., Sieghart W., Biggio G., Braestrup C., Bateson A.N. and Langer S.Z. (1998) International Union of Pharmacology. XV. Subtypes of gamma-aminobutyric acid A receptors: classification on the basis of subunit structure and receptor function. Pharmacol. Rev. 50, 291-313.

Baumann S.W., Baur R. and Sigel E. (2011) Subunit arrangement of gamma-aminobutyric acid type A receptors. J. Biol. Chem. 276, 36275-36280.

Baur R., Tan K.R., Lüscher B.P., Gonthier A., Goeldner M. and Sigel E. (2008) Covalent modification of $\mathrm{GABA}_{\mathrm{A}}$ receptor isoforms by a diazepam analogue provides evidence for a novel benzodiazepine binding site that prevents modulation by these drugs. $J$. Neurochem. 106, 2353-2363.

Boileau A., Baur R., Sharkey L.M., Sigel E. and Czajkowski C. (2002) The relative amount of cRNA coding for $\gamma 2$ subunits affects stimulation by benzodiazepines in $\mathrm{GABA}_{\mathrm{A}}$ receptors expressed in Xenopus oocytes. Neuropharmacol. 43, 695-700.

Buhr A., Schaerer M.T., Baur R. and Sigel E. (1997) Residues at positions 206 and 209 of the $\alpha_{1}$ subunit of gamma-aminobutyric acid A receptors influence affinities for benzodiazepine binding site ligands. Mol. Pharmacol. 52, 676-682.

Ernst M., Bruckner S., Boresch S. and Sieghart W. (2005) Comparative models of GABA extracellular and transmembrane domains: important insights in pharmacology and function. Mol. Pharmacol. 68, 1291-1300.

Jurd R., Arras M., Lambert S., Drexler B., Siegwart R., Crestani F., Zaugg M., Vogt K.E., 
Ledermann B., Antkowiak B. and Rudolph U. (2003) General anesthetic actions in vivo strongly attenuated by a point mutation in the GABA(A) receptor beta3 subunit. FASEB J. 17, 250-252.

Li G.D., Chiara D.C., Sawyer G.W., Husain S.S., Olsen R.W. and Cohen J.B. (2006) Identification of a $\mathrm{GABA}_{\mathrm{A}}$ receptor anesthetic binding site at subunit interfaces by photolabeling with an etomidate analog. J. Neurosci. 26, 11599-11605.

Macdonald R.L. and Olsen R.W. (1994) GABAA receptor channels. Annu. Rev. Neurosci. 17, 569-602.

Maldifassi M.C., Baur R. and Sigel E. (2016) Functional sites involved in modulation of the $\mathrm{GABA}_{\mathrm{A}}$ receptor channel by the intravenous anesthetics propofol, etomidate and pentobarbital. Neuropharmacol. 6, 207-214.

Middendorp S.J., Puthenkalam R., Baur R., Ernst M. and Sigel E. (2014) Accelerated discovery of novel benzodiazepine ligands by experiment-guided virtual screening. A.C.S. Chem. Biol. 9, 1854-1859.

Middendorp S.J., Maldifassi M.C., Baur R. and Sigel E. (2015) Positive modulation of synaptic and extrasynaptic $\mathrm{GABA}_{\mathrm{A}}$ receptors by an antagonist of the high affinity benzodiazepine binding site. Neuropharmacol. 95, 459-467.

Miller P.S. and Aricescu A.R. (2014) Crystal structure of a human GABA receptor. Nature. 512, $270-275$.

Minier F. and Sigel E. (2004) Positioning of the $\alpha$-subunit isoforms confers a functional signature to $\gamma$-aminobutyric acid type A receptors. Proc. Natl. Acad. Sci. U.S.A. 101, 7769-7774.

Nishikawa K., Jenkins A., Paraskevakis I. and Harrison N.L. (2002) Volatile anesthetic actions on the GABA $A_{A}$ receptors: contrasting effects of $\alpha_{1} \mathrm{~S} 270$ and $\beta_{2} \mathrm{~N} 265$ point 
mutations. Neuropharmacol. 42, 337-345.

Olsen R.W. and Sieghart W. (2008) International Union of Pharmacology. LXX. Subtypes of gamma-aminobutyric acid (A) receptors: classification on the basis of subunit composition, pharmacology, and function. Update, Pharmacol. Rev. 60, 243-260.

Rabow L.E., Russek S.J. and Farb D.H. (1995) From ion currents to genomic analysis: recent advances in GABA receptor research. Synapse. 21, 189-274.

Ramerstorfer J., Furtmüller R., Sarto-Jackson I., Varagic Z., Sieghart W. and Ernst M. (2011) The $\mathrm{GABA}_{\mathrm{A}}$ receptor $\alpha+/ \beta$ - interface: a novel target for subtype selective drugs. $J$. Neurosci. 31, 870-877.

Rudolph U., Crestani F., Benke D., Brünig I., Benson J.A., Fritschy J.M., Martin J.R., Bluethmann H. and Möhler H. (1999) Benzodiazepine actions mediated by specific gamma-aminobutyric acid(A) receptor subtypes. Nature. 401, 796-800.

Sigel E. (1987) Properties of single sodium channels translated by Xenopus oocytes after injection with messenger ribonucleic acid. J. Physiol. Lond. 386, 73-90.

Sigel E., Baur R., Trube G., Möhler H. and Malherbe P. (1990) The effect of subunit combination of rat brain GABA A receptors on channel function. Neuron. 5, 703-711.

Sigel E. and Buhr A. (1997) The benzodiazepine binding site of GABAA receptors. Trends Pharmacol. Sci. 18, 425-429.

Sigel E. (2002) Mapping of the benzodiazepine recognition site on GABA(A) receptors. Curr. Top. Med. Chem. 2, 833-839.

Sigel E. and Minier F. (2005) The Xenopus oocyte: system for the study of functional expression and modulation of proteins. Mol. Nutr. Food. Res. 49, 228-234.

Sigel E. and Lüscher B.P. (2011) A closer look at the high affinity benzodiazepine binding

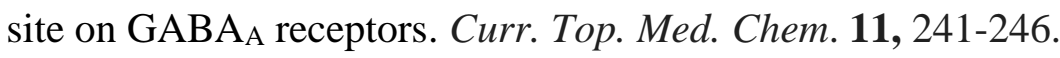


Sigel E. and Steinmann M.E. (2012) Structure, function, and modulation of GABAA receptors. J. Biol. Chem. 287, 40224-40231.

Sieghart W. (1995) Structure and pharmacology of gamma-aminobutyric acid A receptor subtypes. Pharmacol. Rev. 47, 181-233.

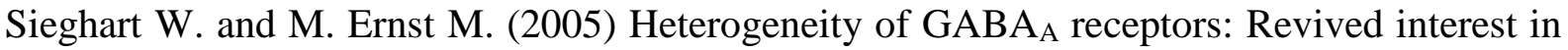
the development of subtype-selective drugs. Curr. Med. Chem. 5, 217-242.

Varagic Z., Wimmer L., Schnürch M., Mihovilovic M.D., Huang S., Rapalli S., Cook J.M., Mirheydari P., Ecker G.F., Sieghart W. and Ernst M. (2013a) Identification of novel positive allosteric modulators and null modulators at the GABAA receptor $\alpha+/ \beta-$ interface. Br. J. Pharmacol. 169, 371-383.

Varagic Z., Ramerstorfer J., Huang S., Rallapalli S., Sarto-Jackson I., Cook I., Sieghart W. and Ernst M. (2013b) Subtype selectivity of the $\alpha+/ \beta$ - site ligands of $\mathrm{GABA}_{\mathrm{A}}$ receptors: identification of the first highly specific positive modulators at $\alpha_{6} \beta_{2 / 3} \gamma_{2}$ receptors. Br. J. Pharmacol. 169, 384-399.

Wallner M., Hanchar H.J. and Olsen R.W. (2014) Alcohol selectivity of $\beta_{3}$-containing $\mathrm{GABA}_{\mathrm{A}}$ receptors: evidence for a unique extracellular alcohol/imidazobenzodiazepine Ro15-4513 binding site at the $\alpha+\beta$ - subunit interface in $\alpha \beta 3 \delta$ GABAA receptors. Neurochem Res. 39, 1118-1126.

Walters R.J., Hadley S.H., Morris K.D. and Amin J. (2000) Benzodiazepines act on GABAA receptors via two distinct and separable mechanisms. Nat. Neurosci. 12, 1274-1281.

Yip G.M., Chen Z.W., Edge C.J., Smith E.H., Dickinson R., Hohenester E., Townsend R.R., Fuchs K., Sieghart W., Evers A.S. and Franks N.P. (2013) A propofol binding site on mammalian GABA $\mathrm{A}_{\mathrm{A}}$ receptors identified by photolabeling. Nat. Chem. Biol. 9, 715-720. 


\section{Legends to figures}

Fig. 1 (a) Model structure of the GABAA receptor transmembrane domain. The receptor is composed of two $\alpha$ (yellow), two $\beta$ (blue), and one $\gamma$ (red) subunits; structures are shown in ribbon representation. Shown in orange are the $\alpha$ Y209 residues located at the extracellular $\alpha+/ \beta-$ and $\alpha+/ \gamma-$ interfaces. The model structure depicts the crystalized homomeric $\beta_{3}$ GABA $A_{A}$ receptor (PDB structure 4COF) (Miller and Aricescu 2014). Some of the $\beta_{3}$ subunits were renamed $\alpha_{1}, \beta_{2}$ and $\gamma_{2}$. (b) Chemical structures of the compounds studied. Right: The investigated compounds differed in their substituents at position R4 and R8. Left: Common pyrazoloquinolinone nucleus.

Fig. 2 Potentiation of wild-type $\alpha_{1} \beta_{2} \gamma_{2}$ and mutated $\alpha_{1} Y 209 Q \beta_{2} \gamma_{2}, \alpha_{1} Y 209 C \beta_{2} \gamma_{2}, \alpha_{1} Y 209 F \beta_{2} \gamma_{2}$ receptors by $10 \mu \mathrm{M}$ CGS 9895. (a) Original current traces showing the potentiation of the GABA elicited response by $10 \mu \mathrm{M}$ CGS 9895 in wild-type (top) and mutant $\alpha_{1} \mathrm{Y}_{209 \mathrm{Q}} \beta_{2} \gamma_{2} \square$ bottom) receptor. Receptors were expressed in Xenopus oocytes and electrophysiological experiments were performed. The holding membrane potential was $-80 \mathrm{mV}$. GABA at a concentration eliciting $0.7-1.2 \%$ of the maximal current amplitude (single bars) was applied twice alone and then in combination with $10 \mu \mathrm{M}$ CGS 9895. The $\alpha_{1}$ Y209Q mutation strongly decreased allosteric modulation. (b) Summary of the results obtained in wild-type, and mutant $\alpha_{1} Y 209 \mathrm{Q} \beta_{2} \gamma_{2}, \alpha_{1} \mathrm{Y} 209 \mathrm{C} \beta_{2} \gamma_{2}$, and $\alpha_{1} \mathrm{Y} 209 \mathrm{~F} \beta_{2} \gamma_{2}$ receptors. Experiments were performed four to eleven times with different oocytes from at least three different batches; data are expressed as mean \pm SEM.

Fig. 3 Potentiation of $\alpha_{1} \beta_{2}$ and mutated $\alpha_{1} Y 209 Q \beta_{2}, \alpha_{1} Y 209 C \beta_{2}, \alpha_{1} Y 209 F \beta_{2}$ receptors by $10 \mu M$ CGS 9895. (a) Original current traces showing the potentiation of the GABA elicited response by $10 \mu \mathrm{M}$ CGS 9895 in oocytes expressing $\alpha_{1} \beta_{2}$ (top) and mutant $\alpha_{1} Y_{2} 209 \beta_{2} \square$ (bottom) receptors. GABA at a concentration eliciting 0.7-1.2 \% of the maximal current amplitude (single bars) was applied twice alone and then in combination with $10 \mu \mathrm{M}$ CGS 9895. (b) Summary of the results obtained in $\alpha_{1} \beta_{2}$, and mutant $\alpha_{1} \mathrm{Y} 209 \mathrm{Q} \beta_{2}, \alpha_{1} \mathrm{Y} 209 \mathrm{C} \beta_{2}, \alpha_{1} \mathrm{Y} 209 \mathrm{~F} \beta_{2}$ receptors. The holding membrane potential was -80 
$m V$. Experiments were performed four to six times in different oocytes from at least three different batches; data are expressed as mean \pm SEM.

Fig. 4 Concentration dependence of the positive allosteric modulation by CGS 9895 in oocytes expressing wild-type (closed circle) and $\alpha_{1} \mathrm{Y}_{2} 09 \mathrm{Q} \beta_{2} \gamma_{2}$ (closed square) receptors. Data are shown as mean $\pm \mathrm{SEM}, \mathrm{n}=4$.

Fig. 5 Mutations at the $\alpha_{1} Y 209$ residue affect potentiation by different structural analogues of CGS 9895. Potentiation of the GABA elicited response by $1 \mu \mathrm{M}$ LAU 177, $4 \mu \mathrm{M}$ LAU 176, $10 \mu \mathrm{M}$ CGS 8216 and $10 \mu \mathrm{M}$ CGS 9896 in wild-type and mutant $\alpha_{1} Y 209 \beta_{2} \gamma_{2}$ receptors. Experiments were performed four to six times using different oocytes; data are expressed as mean \pm SEM.

Fig. 6 Concentration-response curves obtained of flurazepam in wild-type receptors (closed circle), and mutant $\alpha_{1} \mathrm{Y}_{209 \mathrm{Q}} \beta_{2} \gamma_{2}$ receptors (closed square). Experiments were carried out 4-9 times, with three different batches of oocytes. Results are expressed as mean \pm SEM.

Fig. 7 Original current traces showing inhibition of CGS 9895 induced GABAA receptor potentiation by flurazepam (FZM). Wild-type receptors were expressed in Xenopus oocytes. GABA was applied two times, followed by co-application of the same concentration of GABA with $10 \mu \mathrm{M}$ CGS 9895, and finally combined application of GABA with $10 \mu \mathrm{M}$ CGS 9895 and $300 \mu \mathrm{M}$ flurazepam. The holding membrane potential was $-80 \mathrm{mV}$. Experiments were carried out 4 times with three different batches of oocytes, with a similar outcome.

Fig. 8 (a) Concentration dependence of the positive allosteric modulation by diazepam in oocytes expressing different receptors: $\alpha_{1} \beta_{2} \gamma_{2}$ (closed circle), $\alpha_{1} \mathrm{M} \beta_{2} \gamma_{2}$ (inverted triangle), $\alpha_{1} \beta_{2} \mathrm{M} \gamma_{2}$ (square), $\alpha_{1} \beta_{2} \gamma_{2} \mathrm{M}$ (triangle), and $\alpha_{1} \mathrm{M} \beta_{2} \mathrm{M} \gamma_{2} \mathrm{M}$ (gray circle) receptors. Data is represented as mean $\pm \mathrm{SEM}, \mathrm{n}=4$ 5. (b) Summary of the results obtained by $10 \mu \mathrm{M}$ CGS 9895, $10 \mu \mathrm{M}$ LAU 177 , and $200 \mu \mathrm{M}$ diazepam 
in wild-type, single mutant $\alpha_{1} \mathrm{M} \beta_{2} \gamma_{2}, \alpha_{1} \beta_{2} \mathrm{M} \gamma_{2}, \alpha_{1} \beta_{2} \gamma_{2} \mathrm{M}$ and triple mutant $\alpha_{1} \mathrm{M} \beta_{2} \mathrm{M} \gamma_{2} \mathrm{M}$ receptors. The bars indicate mean \pm SEM, $n=4-5$. 